Faraed D Salman BDS, MSc (Lect)

Khawla M Saleh

BDS, MSc (Assist Lect)

Aisha A Qasim

BDS, MSc (Assist Lect)

\section{Dental health status of adult population in Yemen (Thamar City)}

\author{
Dept of Pedod, Orthod and Prev Dent \\ College of Dentistry, University of Mosul
}

\begin{abstract}
Aims: To evaluate the oral health status (dental caries, periodontal disease and treatment needs) in Yemenis adult individuals. Material and Methods: The sample included 471 individuals, age ranging between 20-59 years of both sexes using sharp dental caries explorers with WHO periodontal probes to detect periodontal health by the use of DMFT index of WHO (1997) and CPITN by WHO (1987). Results: The mean DMFT for the total sample was $7.33 \pm 0.3$ which was increased with increasing age for the different age groups with a significant difference but no significant difference in the mean DMFT for total males and females has been found. The results also showed that the total number of teeth (880) with a mean of 1.81 tooth/person in need of treatment is the most prevalent needed one surface filling, and 581 teeth with a mean of 1.23 tooth/ person needed two or more surfaces filling. According to the highest CPITN there was significant difference between male and female in calculus at $p \leq 0.05$ and shallow pockets at $p \leq 0.01$. The results also revealed that the mean number of healthy sextants for the total sample was 4.13 while for bleeding and calculus were 1.02 and 0.21 , respectively. It means that the treatment needs for periodontal disease is more toward oral hygiene procedure and prophylaxis. Conclusion: Dental health education program is an essential activity for promoting optimal oral health and preventing oral diseases.
\end{abstract}

Key Words: Dental health status, DMFT, CPITN.

Salman FD, Saleh KhM, Qasim AA. Dental health status of adult population in Yemen (Thamar City). Al-Rafidain Dent J. 2006; 6(2): 144-150.

Received: 4/12/2005 Sent to Referees: 5/12/2005 Accepted for Publication: 22/12/2005

\section{INTRODUCTION}

Periodontitis is a bacterial infection of all parts of the periodontium including gingiva, periodontal ligament, bone and cementum, which result in irreversible destruction to the tissue of the periodontium. Periodontal disease is one of the most widespread diseases all over the world and more prevalent among population of the developing countries. ${ }^{(1)}$

Periodontal disease usually begins at childhood as gingivitis which increases in prevalence and severity to the early "teen" years and it may lead to the development of periodontitis which is associated with pocket formation and bone resorption in adult population, ${ }^{(2,3)}$ while dental caries is one of the most prevalent infectious disea- ses of man. It is localized progressive demineralization of the hard tissues of the crown (coronal enamel, dentin, root cementum and dentin) surfaces of teeth. ${ }^{(4)}$ Dental caries is age related prevalence beginning soon after tooth eruption in susceptible children and increase with age, ${ }^{(5)}$ and it is most prevalent chronic disease. Once it occurs, its manifestations persist permanently in the form of restoration or tooth loss. ${ }^{(6)}$

There are many factors that affect prevalence and severity of dental caries and periodontal disease, the most important factors are age, $\left.{ }^{(7,}, 8\right)$ sex,${ }^{(9,10)}$ income level, place of residence, parental influence, ${ }^{(11)}$ educational level and socioeconomic status. ${ }^{(12)}$ It has also been associated with kno- 
wledge, attitude and behaviors relating to preventive care..$^{(13-15)}$

Developing countries have experienced a deterioration in oral health due to a change in socio-economic condition, dietary habits and lack of education. ${ }^{(16,17)} \mathrm{On}$ the other hand, the trends of these two major dental diseases in developing countries call for integrated coordinated planning of preventive and treatment services for oral health as an urgent priority. The purposes of this study were to estimate the prevalence and severity of dental caries and periodontal diseases in people of Yemen (Thamar City) of age 20-59 years old and the treatment need for them to obtain data that can help in planning preventive dental health program.

\section{MATERIAL AND METHODS}

The survey was conducted during the period between November 2000 to January 2001 on 471 randomly selected Yemenis adult people seeking for dental treatment in different departments of dental college (in Thamar City), age ranging between 20-59 years old, divided into 4 age groups of 10 years intervals: $20-29,30-39,40-49$ and 50-59 years, respectively.

The clinical examination was carried out by one examiner at the dental college using plane mouth mirrors, sharp dental caries explorers and WHO periodontal probes to detect periodontal health.

The indices used for assessment of dental conditions were as follows:

1. DMFT by WHO methodology for caries status and treatment need (1997) ${ }^{(18)}$ to obtain and calculate Decayed (D), Missing (M) and Filled (F) for each tooth.

2. Community Periodontal Index of Treatment Needs (CPITN) by WHO $(1987)^{(19)}$ for assessment of gingival and periodontal health status and their treatment needs. Each sextant was assigned a code number which recorded the condition of the worst affected site in that sextant. The subjects were classified into treatment need categories according to the highest code number assigned to any of the sextants in particular individual. Additional information regarding this study such as age and sex were recorded on a special form.

The statistical analysis of the data included the means, standard deviation and standard error by using Duncan's Multiple Range Test, analysis of variance (ANOVA), F-test and Kruskal-Wallis test.

\section{RESULTS}

The age and gender distribution of 471 subjects comprising 356 males and 115 females was divided into 4 age groups with an interval of 10 years for each age group (Table 1). The proportion of males was $75.6 \%$, which was much higher than that of females $(24.4 \%)$ as a general rule in Yemen regarding males number to fem-ale number.

Table (2) showed that the mean DMFT and its components DT, MT, FT for the total sample was $7.33 \pm 6.51$. There was no significant difference in the mean DMFT for total males (7.17) and total females (7.50) but there was a significant difference in the mean DMFT and its components between different age groups and the caries prevalence was increased with age for both sexes.

Table (3) illustrated the number of teeth in the total sample that required treatment, it showed that the treatment need for person for the total sample was in need of one surface filling, followed by two or more surfaces filling.

Table (1): Distribution of the sample by age and sex

\begin{tabular}{ccccccc}
\hline Age & \multicolumn{2}{c}{ Male } & \multicolumn{2}{c}{ Female } & \multicolumn{2}{c}{ Total } \\
\cline { 2 - 7 } (Year) & No. & \% & No. & \% & No. & \% \\
\hline $\mathbf{2 0 - 2 9}$ & 173 & 48.6 & 46 & 40.0 & 219 & 46.5 \\
$\mathbf{3 0 - 3 9}$ & 48 & 13.5 & 36 & 31.3 & 84 & 17.8 \\
$\mathbf{4 0 - 4 9}$ & 41 & 11.5 & 18 & 15.7 & 59 & 12.5 \\
$\mathbf{5 0 - 5 9}$ & 94 & 26.4 & 15 & 13.0 & 109 & 23.2 \\
\hline Total & 356 & 75.6 & 115 & 24.4 & 471 & 100.0 \\
\hline
\end{tabular}


Table (2): The mean DMFT and its components

\begin{tabular}{|c|c|c|c|c|c|c|c|c|c|c|c|c|c|c|}
\hline \multirow{2}{*}{$\begin{array}{c}\text { Age } \\
\text { (Year) }\end{array}$} & \multirow{2}{*}{ Sex } & \multirow{2}{*}{ No. } & \multicolumn{3}{|c|}{ DMFT } & \multicolumn{3}{|c|}{ DT } & \multicolumn{3}{|c|}{ MT } & \multicolumn{3}{|c|}{ FT } \\
\hline & & & Mean & \pm SD & SE & Mean & \pm SD & SE & Mean & \pm SD & SE & Mean & $\pm \mathrm{SD}$ & SE \\
\hline \multirow{3}{*}{ 20-29 } & Male & 173 & 4.12 & 4 & 0.33 & 3.53 & 3.95 & 0.30 & 0.13 & 53 & 0.04 & 0.46 & 1.18 & 0.09 \\
\hline & Female & 46 & 70 & 4.34 & 0.64 & 2.94 & 3.93 & 0.58 & 0.22 & 68 & .10 & .54 & 56 & 0.23 \\
\hline & Total & 219 & $3.91^{\mathrm{d}}$ & 29 & 0.29 & $3.41^{\mathrm{c}}$ & 3.85 & 0.26 & $0.10^{\mathrm{c}}$ & 59 & 04 & $40^{\mathrm{b}}$ & 33 & 0.09 \\
\hline \multirow{3}{*}{ 30-39 } & Male & 48 & & 4.99 & 0.72 & & 3.81 & 0.55 & 0.50 & 1.59 & & 50 & .59 & 0.23 \\
\hline & Female & 36 & $6.67^{\mathrm{AB}}$ & 4.50 & 0.75 & 5.88 & 4.56 & 0.76 & 0.62 & 1.08 & 0.18 & 0.17 & 0.54 & 0.09 \\
\hline & Total & 84 & $6.00^{C}$ & 4.95 & 0.54 & $5.10^{\mathrm{b}}$ & 4.22 & 0.46 & $0.56^{\mathrm{c}}$ & 1.47 & 0.16 & $0.34^{\mathrm{b}}$ & 1.37 & 0.15 \\
\hline \multirow{3}{*}{$40-49$} & Male & 41 & 10.29 & 4.74 & 0.74 & 7.61 & 4.03 & 0.63 & 1.50 & 2.37 & 0.37 & 1.18 & 1.66 & 0.26 \\
\hline & Female & 18 & 11.49 & 5.77 & 1.36 & 7.11 & 3.56 & 0.84 & 3.19 & 4.54 & 1.07 & 1.19 & 1.82 & 0.43 \\
\hline & Total & 57 & $10.88^{\mathrm{b}}$ & 4.9 & 0.66 & $7.36^{\mathrm{a}}$ & 3.85 & 0.51 & $2.34^{\mathrm{b}}$ & 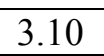 & 0 & $1.18^{\mathrm{a}}$ & 1.66 & 0.22 \\
\hline \multirow{3}{*}{ 50-59 } & & 94 & 12.35 & 61 & 0.70 & 6.87 & 4.27 & 0.44 & 4.46 & 4 & 0 . & 1.01 & 1.75 & 0.18 \\
\hline & Female & 15 & 14.47 & 6.43 & 1.66 & 8.87 & 4.65 & 1.20 & 4.87 & 3.95 & 1.02 & 0.67 & 1.16 & 0.30 \\
\hline & Total & 109 & $13.41^{\mathrm{a}}$ & 6.68 & 0.64 & $7.87^{\mathrm{a}}$ & 8.56 & 0.82 & $4.66^{\mathrm{a}}$ & 5.32 & 0.51 & $0.84^{\mathrm{a}}$ & 1.67 & 0.16 \\
\hline \multicolumn{2}{|c|}{ Total Males } & 356 & 7.17 & 6.42 & 0.34 & 4.99 & 4.34 & 0.23 & 1.49 & 3.58 & 0.19 & 0.69 & 1.51 & 0.08 \\
\hline \multicolumn{2}{|c|}{ Total Females } & 115 & 7.50 & 6.43 & 0.60 & 5.24 & 4.61 & 0.43 & 1.70 & 3.00 & 0.28 & 0.56 & 1.39 & 0.13 \\
\hline \multicolumn{2}{|c|}{ Total } & 471 & 7.33 & 6.51 & 0.30 & 5.11 & 4.34 & 0.20 & 1.59 & 3.47 & 0.16 & 0.62 & 1.52 & 0.07 \\
\hline
\end{tabular}

SD: Standard deviation; SE: Standard error.

Different letters vertically mean significant difference at $p \leq 0.05$.

Table (3): Dental treatment need

\begin{tabular}{lcc}
\hline \multicolumn{1}{c}{ Type of Dental Treatment } & No. of Teeth & Treatment Need/Person \\
\hline One Surface Filling & 880 & 1.81 \\
Two or More Surfaces Filling & 581 & 1.28 \\
Veneer & 5 & 0.01 \\
Extraction & 37 & 0.08 \\
Pulp Care & 14 & 0.03 \\
Crown or Removable Replacement & 302 & 0.64 \\
\hline
\end{tabular}

Table (4) showed that the total sample distributed according to the highest CPITN code by age and sex. It has been found that only 264 persons (56.1\%) are healthy in all age groups and the highest percentage was in the last age group (50-59) years. The most frequently periodontal condition was calculus. It has been found that significant difference between males and females for calculus, at $p \leq 0.05$, and deep pockets, at $p \leq 0.01$, existed.

The prevalence of gingival bleeding was higher in the first age group and lowest in the fourth age group.

Differences between different age groups concerning males were found to be significant at $p \leq 0.01$ level but not for females except in code 1 (bleeding).

Table (5) showed the mean number of sextants by person. The mean number of healthy sextants for the total sample was
4.13, while for bleeding and calculus were 1.02 and 0.21 , respectively.

The mean number of healthy sextant for all age groups were nearly the same, while bleeding code was decreased with increasing age. The mean number for calculus and pocket sextants was increased with age but not for all age groups.

Females tended to have healthier and had less bleeding and calculus sextants compared to males.

Table (6) demonstrated the distribution and percentage of sample in need to oral hygiene education, scaling and those with no need for treatment. More than half of the sample (about 56.1\%) showed no need to any type of periodontal treatment (score 0) and less than half of the sample $(43.9 \%)$ need oral hygiene instruction, while $23.6 \%$ of sample need scaling. 
Table (4): Number and percentage of sample distributed according to highest CPITN code by age and sex

\begin{tabular}{|c|c|c|c|c|c|c|c|c|c|c|c|c|c|c|c|c|c|c|}
\hline \multirow{2}{*}{\multicolumn{3}{|c|}{$\begin{array}{c}\begin{array}{c}\text { Age } \\
\text { (Year) }\end{array} \\
\text { Sex } \\
\end{array}$}} & \multicolumn{3}{|c|}{ 20-29 } & \multicolumn{3}{|c|}{ 30-39 } & \multicolumn{3}{|c|}{$40-49$} & \multicolumn{3}{|c|}{ 50-59 } & \multicolumn{2}{|c|}{ Total } & \multirow[t]{2}{*}{ Total } & \multirow{3}{*}{$p$-value } \\
\hline & & & $\mathbf{M}$ & $\mathbf{F}$ & $\mathbf{T}$ & $\mathbf{M}$ & $\mathbf{F}$ & $\mathbf{T}$ & $\mathbf{M}$ & $\mathbf{F}$ & $\mathbf{T}$ & $\mathbf{M}$ & $\mathbf{F}$ & $\mathbf{T}$ & $\mathbf{M}$ & $F$ & & \\
\hline & No. & & 173 & 46 & 219 & 48 & 36 & 84 & 41 & 18 & 59 & 94 & 15 & 109 & 356 & 115 & 471 & \\
\hline \multirow{10}{*}{ 总 } & n & No. & 73 & 23 & 96 & 31 & 25 & 56 & 27 & 12 & 39 & 63 & 10 & 73 & 194 & 70 & 264 & 01) \\
\hline & 0 & $\%$ & 42.2 & 50.0 & 43.8 & 64.6 & 69.4 & 66.7 & 65.8 & 66.7 & 66.1 & 67.0 & 66.6 & 67.0 & 54.5 & 60.9 & 56.1 & )NS \\
\hline & & No. & 47 & 15 & 62 & 4 & 2 & 6 & 4 & 2 & 6 & 1 & 0 & 1 & 56 & 19 & 75 & M (< \\
\hline & 1 & $\%$ & 27.2 & 32.6 & 28.3 & 8.3 & 5.6 & 7.1 & 9.8 & 11.1 & 10.1 & 1.1 & 0.0 & 0.9 & 15.7 & 16.5 & 15.9 & .01) \\
\hline & ? & No. & 46 & 5 & 51 & 8 & 7 & 15 & 4 & 1 & 5 & 12 & 3 & 15 & 70 & 16 & 86 & $\mathrm{M}$ \\
\hline & & $\%$ & 26.6 & $10.9^{*}$ & 23.3 & 16.7 & 19.4 & 17.8 & 9.8 & 5.6 & 8.5 & 12.7 & 20.6 & 13.8 & 19.7 & 13.9 & 18.3 & $\mathrm{~F}(>$ \\
\hline & 2 & No. & 7 & 1 & 8 & 3 & 2 & 5 & 3 & 3 & 6 & 14 & 1 & 15 & 27 & 7 & 34 & $\mathrm{M}(<0.05)$ \\
\hline & 3 & $\%$ & 4.0 & 2.2 & 3.7 & 6.3 & 5.6 & 6.0 & 7.3 & 16.6 & 10.2 & 14.9 & 6.7 & 13.8 & 7.6 & 6.1 & 7.2 & $\mathrm{~F}(>0.05) \mathrm{NS}$ \\
\hline & & No. & 0 & 2 & 2 & 2 & 0 & 2 & 3 & 0 & 3 & 4 & 1 & 5 & 9 & 3 & 12 & $\mathrm{M}(<0.05)$ \\
\hline & 4 & $\%$ & 0.0 & $4.3^{* *}$ & 0.9 & 4.2 & 0.0 & 2.4 & 7.3 & 0.0 & 5.1 & 4.3 & 6.7 & 4.6 & 2.5 & 2.6 & 2.5 & $\mathrm{~F}(>0.05) \mathrm{NS}$ \\
\hline
\end{tabular}

Scores: 0: Healthy; 1: Bleeding; 2: Calculus; 3: Shallow pocket; 4: Deep pocket.

M: Male; F: Female; T: Total; NS: Not significant.

* Significant difference between males and females at $p \leq 0.05$ using $\chi^{2}$ test.

** Significant difference between males and females at $p \leq 0.01$ using $\chi^{2}$ test.

Kruskal-Wallis test was used between age groups.

Table (5): Mean number of sextants affected per person for each stage of disease by age and sex

\begin{tabular}{|c|c|c|c|c|c|c|c|c|c|c|c|c|c|c|c|c|c|}
\hline \multirow{2}{*}{\multicolumn{3}{|c|}{$\frac{\text { Age (Year) }}{\text { Sex }}$}} & \multicolumn{3}{|c|}{ 20-29 } & \multicolumn{3}{|c|}{$30-39$} & \multicolumn{3}{|c|}{$40-49$} & \multicolumn{3}{|c|}{ 50-59 } & \multicolumn{2}{|c|}{ Total } & \multirow{2}{*}{ Total } \\
\hline & & & $\mathbf{M}$ & $\mathbf{F}$ & $T$ & $\mathbf{M}$ & $\mathbf{F}$ & $T$ & $\mathbf{M}$ & $\mathbf{F}$ & $\mathbf{T}$ & $\mathbf{M}$ & $\mathbf{F}$ & $\mathbf{T}$ & $\mathbf{M}$ & $\mathbf{F}$ & \\
\hline & $\mathbf{N}$ & & 173 & 46 & 219 & 48 & 36 & 84 & 41 & 18 & 59 & 94 & 15 & 109 & 356 & 115 & 471 \\
\hline \multirow{10}{*}{ 㫕 } & & Mean & 3.80 & 4.21 & 4.01 & 4.61 & 4.55 & 4.58 & 4.02 & 4.38 & 4.20 & 4.26 & 4.13 & 4.19 & 4.03 & 4.24 & 4.13 \\
\hline & 0 & \pm SD & 2.1 & 2.1 & 2.07 & 2.36 & 2.64 & 2.47 & 2.5 & 2.46 & 2.46 & 2.52 & 2.71 & 2.51 & 2.26 & 2.36 & 7 \\
\hline & 1 & Mean & 1.38 & 1.25 & 1.32 & 0.92 & 0.95 & 0.94 & 0.82 & 0.74 & 0.78 & 0.55 & 0.50 & 0.53 & 1.04 & 0.99 & .02 \\
\hline & 1 & \pm SD & 1.45 & 1.63 & 1.48 & 1.59 & 1.74 & 1.65 & 1.28 & 1.48 & 1.31 & 0.97 & 0.97 & 0.21 & 0.38 & 1.61 & 0.43 \\
\hline & & Mean & 0.75 & 0.34 & 0.54 & 0.16 & 0.35 & 0.25 & 0.29 & 0.30 & 0.29 & 0.32 & 0.35 & 0.34 & 0.22 & 0.20 & 0.21 \\
\hline & 2 & $\pm \mathrm{SD}$ & 1.32 & 0.81 & 12.7 & 0.9 & 1.32 & 1.1 & 1.15 & 1.06 & 1.15 & 1.26 & 0.97 & 1.25 & 0.38 & 1.07 & 0.43 \\
\hline & 3 & Mean & 0.07 & 0.10 & 0.08 & 0.29 & 0.15 & 0.22 & 0.64 & 0.46 & 0.55 & 0.55 & 0.67 & 0.61 & 0.45 & 0.36 & 0.41 \\
\hline & 3 & \pm SD & 0.26 & 0.41 & 0.3 & 1.04 & 1.2 & 1.28 & 0.9 & 1.23 & 1.0 & 0.19 & 1.59 & 1.04 & 0.38 & 0.21 & 0.43 \\
\hline & 4 & Mean & 0.00 & 0.10 & 0.05 & 0.02 & 0.00 & 0.01 & 0.23 & 0.12 & 0.18 & 0.32 & 0.35 & 0.33 & 0.26 & 0.21 & 0.23 \\
\hline & 4 & \pm SD & 0.0 & 0.47 & 0.15 & 0.14 & 0.0 & 0.18 & 0.13 & 0.08 & 0.15 & 0.19 & 0.77 & 0.21 & 0.38 & 0.21 & 0.43 \\
\hline
\end{tabular}

Scores: 0: Healthy; 1: Bleeding; 2: Calculus; 3: Shallow pocket; 4: Deep pocket.

M: Male; F: Female; T: Total; SD: Standard deviation.

Table (6): Periodontal treatment needs expressed as percentage of sample distributed according to type of treatment required by age and sex

\begin{tabular}{|c|c|c|c|c|c|c|c|c|c|c|c|c|c|c|c|c|c|}
\hline \multirow{2}{*}{\multicolumn{3}{|c|}{$\begin{array}{c}\text { Age (Year) } \\
\text { Sex }\end{array}$}} & \multicolumn{3}{|c|}{$20-29$} & \multicolumn{3}{|c|}{ 30-39 } & \multicolumn{3}{|c|}{$40-49$} & \multicolumn{3}{|c|}{ 50-59 } & \multicolumn{2}{|c|}{ Total } & \multirow[b]{2}{*}{ Total } \\
\hline & & & $\mathbf{M}$ & $\mathbf{F}$ & $\mathbf{T}$ & $\mathbf{M}$ & $\mathbf{F}$ & $\mathbf{T}$ & $\mathbf{M}$ & $\mathbf{F}$ & $\mathbf{T}$ & $\mathbf{M}$ & $\mathbf{F}$ & $T$ & $\mathbf{M}$ & $\mathbf{F}$ & \\
\hline & No. & & 173 & 46 & 219 & 48 & 36 & 84 & 41 & 18 & 59 & 94 & 15 & 109 & 356 & 115 & 1 \\
\hline \multirow{8}{*}{ 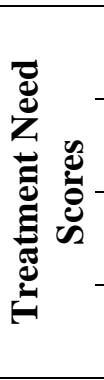 } & & Mean & 73 & 23 & 96 & 31 & 25 & 56 & 27 & 12 & 39 & 63 & 10 & 73 & 4 & 70 & \\
\hline & 0 & \pm SD & 42.2 & 50.0 & 43.8 & 64.6 & 69.4 & 66.7 & 65.8 & 66.7 & 66.1 & 67.0 & 66.6 & 67.0 & 54.5 & 00 & 1 \\
\hline & 1 & Mean & 100 & 23 & 123 & 17 & 11 & 28 & 14 & 6 & 20 & 31 & 5 & 36 & 162 & 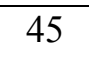 & 20 \\
\hline & 1 & $\pm \mathrm{SD}$ & 57.8 & 50.0 & 56.2 & 35.5 & 30.6 & 33.3 & 34.2 & 33.3 & 34.0 & 33.0 & 33.4 & 30.0 & 45.5 & 39.1 & 43.9 \\
\hline & $?$ & Mean & 53 & 8 & 61 & 13 & 9 & 22 & 10 & 4 & 11 & 26 & 5 & 35 & 106 & 26 & 120 \\
\hline & 2 & \pm SD & 30.6 & 17.4 & 27.9 & 27.2 & 25.0 & 26.2 & 24.4 & 22.2 & 23.8 & 27.7 & 33.4 & 32.1 & 29.8 & 22.6 & 23. \\
\hline & 3 & Mean & 0 & 2 & 2 & 2 & 0 & 2 & 3 & 0 & 3 & 4 & 1 & 5 & 9 & 3 & 12 \\
\hline & 3 & \pm SD & 0.0 & 4.3 & 0.9 & 4.2 & 0.0 & 2.4 & 7.3 & 0.0 & 5.1 & 4.3 & 6.7 & 4.6 & 2.5 & 2.6 & 2.5 \\
\hline
\end{tabular}

Treatment need: 0: No need; 1: Oral hygiene instruction; 2: Scaling; 3: Oral Hygiene instruction + scaling.

M: Male; F: Female; T: Total; SD: Standard deviation. 


\section{DISCUSSION}

Caries experience was measured by the DMFT index, which is valid, simple and reproducible index for assessment of dental caries. This method ensures that the data collected in a wide range of environment is comparable. It also provides a standard measurement of oral disease and condition as a base for planning and evaluating oral health.

The results of this study have shown that there was increase in caries prevalence with increasing age for both sexes. This result was in accordance with many studies conducted in the developing and developed countries. ${ }^{(20-22)}$ This increase in caries experience with age may be attributed to differences in dietary habits, also irreversibility and accumulative nature of dental caries.

The results of this study have also shown that there was no significant difference in the mean DMFT values for total males (7.17) and total females (7.50). This was in accordance with studies conducted in developed and developing countries. ${ }^{(11,21)}$

The ratios of the components to the DMFT were as follows: DT/DMFT= $69.71 \%, \mathrm{MT} / \mathrm{DMFT}=21.69 \%, \mathrm{FT} / \mathrm{DMFT}=$ $8.45 \%$; the highest proportion was for decayed teeth. This may indicate that the therapeutic dental services are limited due to inadequacy and lack of awareness since therapeutic measures are expensive and resources are restricted because Republic of Yemen is a primitive country, so great emphasis should be directed toward primary prevention of the disease and dental health education of the population by control the availability of sugar containing products, confections, drinks and the decrease of sugar consumption. The percentage of population receiving dental care in Republic of Yemen is $2-3 \%$ according to WHO reports of 1996 which is regarded very low. ${ }^{(23)}$

Concerning treatment needs, it has been shown that majority of the sample required one surface filling followed by 2 or more surfaces filling. This was in contrast with a study conducted on adult population in Spain. ${ }^{(21)}$

The main concern of the existing services is to satisfy the current curative dem- ands. This does not comply with the philosophy of a preventive approach because of lack of materials, instruments and non functioning equipment. Such services are of ambulatory nature (concerning on tooth extraction) with negligible restorative care, so pre-requisitic to such a strategy is the continuous development of an active oral health human resources relevant to country needs and resources.

The world wide acceptance of the CPITN, which has proved to be simple and effective method for measuring and monitoring the prevalence and severity of periodontal disease at the community level. ${ }^{(24)}$ The CPITN has been increasingly adopted in dental health services and has proven to be a useful tool for planning and monitoring periodontal treatment and establishing population periodontal health goals. ${ }^{(25,26)}$

This study is the first study conducted on individuals in Yemen using CPITN index to estimate the prevalence of periodontal disease and to assess their periodontal treatments needs.

The results of this study have demonstrated that the healthy gingiva is found in about more than half of the sample $(56.1 \%)$ and the highest percentage was in the last age group. This finding was in contrast to many studies which stated that prevalence of periodontal disease was found in about $100 \%$ in adults 35 years of age and older. ${ }^{(27,28)}$

Results also revealed that there was a significant difference between males and females in calculus at $p \leq 0.05$ and pocket more than $5 \mathrm{~mm}$ depth at $p \leq 0.01$ level. Females tended to have higher percentage of healthy gingiva. This may be due to the fact that there were differences in practice of oral hygiene between sexes; girls tend to practice better oral hygiene. This results was in agreement with other study. ${ }^{(25)}$

The results showed that calculus was the most frequently observed periodontal condition in the total population while in the age group 40-49 years the periodontal condition most frequently observed was shallow pockets.

The findings of this study suggested that periodontal disease prevalence range from low to moderate, so when compared 
with other studies; e.g., age 30-39 years, it is regarded lower to those in Hong Kong, Hungary and Japan, while they are comparable to Australia, New Zealand and Zembaboue. ${ }^{(29)}$ If this result compared with a study conducted in a rural area in Ninevah City in Iraq, it is regarded lower than that. ${ }^{(30)}$

The prevalence of gingival bleeding was higher in the first age group and lower in the fourth age groups. This result was in agreement with that of other studies, ${ }^{(29-31)}$ but disagreed with other study. ${ }^{(21)}$

The mean number of health sextants for all age groups are nearly the same as the bleeding which will decrease with increasing age. It was in agreement with other studies. $^{(25,29,30)}$ The findings of this study indicated that periodontal disease is not prevalent in this population and the cumulative effect of past periodontal breakdown decrease with age, and for majority of subjects the progress of periodontal disease is slow and seems to be compatible with the retention of a natural dentition.

The results indicated that treatment need for periodontal disease is more toward oral hygiene procedure followed by scaling, so this result was in agreement with the result of other studies, ${ }^{(25,31,32)}$ but disagreed with that conducted in Brazil. ${ }^{(33)}$ So the priority should be based on population strategy and primary prevention programs to improve the periodontal health of the majority of people.

\section{CONCLUSION}

Dental caries and periodontal disease are very important public health problems in the most of developing countries. Therefore, an efficient dental health care instruction program should be constructed to achieve an acceptable standard of oral hygiene, so dental health education program for those people is an essential activity for promoting, establishing and maintaining optimal oral health and preventing oral diseases. The need for treatment was concentrated on instruction in oral hygiene and prophylaxes which can be developed by dental hygiene staff as not used in Yemen which would provide improvement in public oral health and at a more accessible cost benefit relationship.

\section{REFERENCES}

1. Jill S, Gehrig N, Donald E. Foundation of Periodontics for the Dental Hygienist. $2^{\text {nd }}$ ed. Lippincott Williams and Wilkins. 2003; Pp: 130-135.

2. Carranza FA. Etiology of periodontal disease. In: Carranza EA, Newman MG. Clinical Periodontology. $8^{\text {th }}$ ed. WB Saunders Co. Philadelphia. 1996; Pp: 158-159.

3. Harris NO, Christen AG. Primary Preventive Dentistry. $4^{\text {th }}$ Ed. Stamford. Connecticut. 1994; Pp: 120-125.

4. Hunt RJ. Behavioral and sociodemographic risk factors for caries. In: Bader JD (ed). Risk Assessment in Dentistry. Chapel Hill University of North Carolina Dental Ecology. 1990; Pp: 50-59.

5. Reid DBW, Grainger RM. Variation in the caries susceptibility of children's teeth. Human Biol. 1995; 27: 1-11.

6. Satish $\mathrm{CH}$, Shaleen CH. Plaque and dental disease. In: Textbook of Preventive Dentistry $1^{\text {st }}$ ed. Delhi. 1999; Pp: 1323.

7. Hussein SA, Doumit M, Doughan BN, El-Nadeef M. Oral health in Lebanon of pilot pathfinder survey. East Mediterr Health J. 1996; 2: 299-303.

8. Skay K, Ship JA. The importance of oral health in the older patient. $J A m$ Geriatr Soc. 1995; 43(12): 141-142.

9. Petersen PE, Razanamihaja N. Oral health status in children and adult in Madagascar. Int Dent J. 1996; 46: 41-47.

10. Al-Naimi RJ. Oral health status and treatment need in 13-15 years old students in Mosul City, Iraq. MSc thesis. College of Dentistry. University of Mosul. 1998.

11. Watson MR, Horowitz AM, Careia I, Canto MT. Caries condition among 2-5 years old immigrant Latino children related to parent's oral health knowledge, opinions and practices. Community Dent Oral Epidemiol. 1999: 27: 8-15.

12. Salbi ZD. A comparison of oral health status, dental health knowledge, behaviour among 13-14 years old school student from two distinct social status area in the city of Baghdad. MSc thesis. College of Dentistry. University of Baghdad. 1999.

13. Murrary JJ, Nunn JH, Steele JG. The 
Prevention of Oral Disease. $4^{\text {th }}$ ed. Oxford, New York. 2003; Pp: 37-58.

14. Jenkins WMM, Papapanou PN. Epidemiology of periodontal disease in children and adolescents. Periodontol. 2000; 26: 16-32.

15. Hayes C. The effect of non cariogenic sweeteners of the prevention of dental caries: A review of the evidence. $J$ Dent Educ. 2001; 65(10): 1106-1109.

16. Al-Naimi RJ. Dental caries experience of rural and urban school children in Ninevah province. A comparative study. Al-Rafidain Dent J. 2001; 1(1): 1823.

17. Walker A, Grogory J, Bradnock G, Nunn J, White D. National diet and nutrition survey: Young people aged 4 to 18 years. Report of the Oral Health Survey. Vol. 2. London HMSO. 2000; Pp: 28-30.

18. World Health Organization. Oral Health Survey: Basic Methods. $4^{\text {th }}$ ed. WHO. Geneva, Switzerland. 1997.

19. World Health Organization. Oral Health Survey: Basic Methods. $3^{\text {rd }}$ ed. WHO. Geneva, Switzerland. 1987.

20. Boross E, Molnar L. Caries intensity and oral hygiene in adult dental patient in Budapest. J Fogory Sz. 1995; 88(3): 95-102.

21. Al-Varaz AA, Al-Varaz RJA, Dena LJM, Fernandez VJ, Villa UM. DMFT and treatment needs in adult population of Oviedo, Spain. Community Dent Oral Epidemiol. 1996; 24(1): 17-20.

22. Kallio P, Murtammaa H. Determinant of self assessed gingival health among adolescents. Acta Odontal Scand. 1997; 55: 106-110.

23. World Health Organization. Report on Regional Training Workshop for Trainers on a Traumatic Restorative Treatment (ART). WHO Regional Office for the Eastern Mediterranean, Alexandria,
Egypt. 1996.

24. Pilot T, Miyasaki H. Global results: 15 years of CPITN epidemiology. Int Dent J. 1994; 44: 553-560.

25. Dini EI. Changes in periodontal conditions of children and adolescents from Araraquara, Brazil. Braz Dent J. 2001; 12(1): 51-55.

26. Oliver RC, Brown LJ, Löe H. Periodontal disease in the United States population. J Periodontol. 1998; 69(2): 269278.

27. Sheiham A. The prevalence and severity of periodontal disease in British populations Br Dent J. 1969; 126: 115-122.

28. Dini EI. Periodontal conditions and treatment needs (CPITN) in a worker population in Araraquara Sp, Brazil. Int Dent J. 1994, 44: 309-311.

29. Pilot T, Barmes DE, Ieclereq MH, McCombie BJ, Sardo Infirri J. Periodontal conditions in adults 35-44 years of age: an overview of CPITN data in the WHO global oral data bank. Community Dent Oral Epidemiol. 1986, 14: 310312.

30. Khamarco TY, Makani LA. Dental health status in Al-Sada and Bahwiza Villages, Ninevah City, Iraq. Iraqi Dent $J$. 1997, 20: 2-23.

31. Khamarco TY. Assessment of periodontal disease using the CPITN index in rural population in Ninevah Iraq. East Mediterr Health J. 1999; 5(3): 549555.

32. Makani LA. Oral hygiene and gingival health among adolescents and adult population (15-44) years in Sharkhan village, Ninevah. Iraq. Al-Rafidain Dent J. 2001. 1(1): 1-7.

33. Lopez NJ, Rios V, Fernandez O. Periodontal conditions in 15-19 years old Chileans. Int Dent J. 1996. 46: 161169. 